injury. The project is unique because it is the first to address backyard farm injuries in Romania. This data will provide the first public health information about backyard farm injuries, which will provide a baseline for future research projects on rural injuries as well as frame backyard farm injury prevention strategies and policies.

\section{BACKYARD FARM INJURIES ASSESSIMENT IN RURAL AREA OF CLUJ COUNTY, ROMANIA}

DRus*, RMChereches, FOprescu, IADirle,CPeek-Asa, AStromquist Correspondence: Babes Bolyai University, Institute for Social Research, Center for Health Policy and Public Health, 71 Traian Mosoiu street, Cluj-Napoca, Romania, 400132, Romania

10.1136/ip.2010.029215.527

Although $46 \%$ of the Romanian population lives in rural areas, little is known about injuries and violence rural residents experience. Research worldwide consistently shows that farm related activities are a major cause of rural injuries. While such injuries can result in considerable suffering and financial losses, little data are available on the prevalence and potential causes of injuries, especially among small farming operations. In Romania, the majority of farming operations are backyard farms, which are a method of survival agriculture, and also provide a place for work and recreation. This project assessed the burden of farm injuries, populations at risk and injury risk factors among backyard family farms in Cluj-Napoca, Romania. 150 backyard farms were targeted, with data collected on injury occurrence, defined as an injury that restricted rural inhabitants from normal activities for at least $4 \mathrm{~h}$, or resulted in loss of consciousness, loss of awareness, or loss of memory for any length of time, or required professional care including backyard farm workers, non-working rural residents and visitors. At the time of abstract submission, data is being collected. Data will include the prevalence and risk factors for 